\title{
Different Phenomena for the Transformation of Multi -functionality of Domestic Spaces and Relevant Product Use Practices
}

abstract In this paper, it is aimed to perform a reading on the different qualities of the notion of the multi-functionality of the domestic space and relevant units, furniture, artefacts and items through three different phenomena that have emerged throughout the analysis of the repertoire of the home cultures of Turkish society. Firstly, the phenomenon of 'Multi-functional Central Space and the Mobile Objects' which traditional and local lifestyles dominate is considered. After that, the multifunctionality qualities of the domestic space and the related units are analysed through the adoption process with modernization and Westernization tendencies after the foundation of Turkish Republic. Along with the analysis of the dichotomies between the family sitting room and the living room and related use notions, the phenomenon of 'Multi-functional Sitting Room and the Inconspicuous Objects' is defined and interpreted. For the contemporary era, the multifunctionalities of the living room and the furniture is considered through everyday practices to the living room area which has also a more informal identity than the previous periods. In this case, the multi-uses of the stable furniture together with different equipments are discussed. For the analysis of the contemporary living rooms and furniture, the recent issues of the home magazines were analysed. Through this analysis, the third phenomenon around the multi-functionality axe emerged: 'Multi-functional Living Room and the Multi-functional Objects'.

keywords multifunctional, function, use, living room, domestic space

\section{Introduction}

The use practices of domestic space and products evolve and transform together with the social transformations in every culture. Considering the home cultures in Turkey, it is possible to observe the transformations about home material culture and use practices conducted with the objects inside the domestic space. In this context, different modes of practices about spaces and objects could be mentioned starting from the nomadic lifestyles and domestic settings, and to be continued with traditional Turkish houses of the Ottoman Empire, 'Westernized' domestic settings after the foundation of Turkish Republic until the contemporary home cultures.

This paper aims to discuss the different perspectives of domestic settings around the axis of the notion of multi-functionality which has become an established term in the context of design. It signifies an approach where an object is equipped with more than just one function, and where users can choose between the available functions (Brandes, 2009). This notion is analyzed together with the domestic spaces also as the multi-functional 
qualities of the space can attribute different features to the objects. The discussion is developed through three different qualities of multi-functionality of the domestic spaces and their interaction and relation with the products:

1. Multi-functional Central Space and the Mobile Objects

2. Multi-functional Sitting Room and the Inconspicuous Objects

3. Multi-functional Living Room and the Multi-functional Objects

These phenomena are defined and named according to the forms and the ways that the objects accompany the multi-functional qualities of the space. Every phenomenon is supposed to depict a certain relationship and interaction between the multi-functional domestic spaces and the furniture and objects that are used inside.

It is undeniable to trace a line of transformation but it is hardly possible to divide the time periods into homogenous slices for explaining some certain practices. It has been analyzed that in the same time period, different domestic practices are being conducted according to the location of the houses, demographic segment of the household throughout the country. So in this study, it was not preferred to develop the analysis under the estimation of the existence of mono block time eras.

\section{Multi-functional Central Space and the Mobile Objects}

This phenomenon emerged through the analysis of the dynamic multi-functional uses of the central space of the rooms of the traditional Turkish houses which was considered as an important phenomenon for discussing the multi-functionality of domestic spaces and even having a design potential for carrying for contemporary uses (Nasır, 2012).

As Faroqhi (2009) indicates, traditional Turkish houses represent a variety of forms and types depending on the location and the era. But considering the scope of this study some common properties and qualities are referred. In the scope of this study, traditional Turkish houses are taken as the traditional dwelling types that were adopted before the industrialization and modernization processes.

In the traditional Turkish houses, the room was an important space unit and it was difficult to mention about functional differentiation throughout the rooms (Günay,1999; Yürekli ve Yürekli, 2005). As Kıray (2006) indicates, in the non - differentiated and non-separated domestic setting, the functions were achieved in an elementary level. There were some basic units for sitting on and storing things. Even if the measurement and the locations of the rooms differed, their use qualities showed similarities. A multi-functional space was especially kept for affording various functions in the middle of the room. In this 'middle space' activities like eating, preparing meals, bathing children, sleeping were conducted. In this phenomenon, the multi-functionality of the space was achieved and created by the assembling/ disassembling processes of the object combinations that were utilized to fulfill a certain function. The units accompanying a certain function had the qualities of being mobile which means being light in weight, easy to move and carry. Through this relationship between space and objects, it is seen that the multi-functional qualities of the space and the mobile qualities of the objects are considered to accompany, reinforce and consolidate each other.

For example, in the eating practice, first a cover is laid down in the middle of the space. An eating platform unit which had a low height, low weight and a circular form was carried and placed on the cover. These qualities enable the unit to be carried and moved easily. 
Even by its circular form, it was possible to move it like turning a wheel.

Accompanying the eating platform, other units and equipments were also sustaining 'mobile' and 'multi-functional' practices. Sitting on the floor and eating from the same dish were common practices which enabled of the occupation of minimum element. If the next action was sleeping, the sleeping mattresses and blankets were taken out from the storage units and placed on the floor in the central space. The sleeping equipments were fabric- based, lightweight and easy to carry. They did not have furniture structure. In the morning, they were folded and put into the storage units so that the central space could be ready for another function. All these mobile properties of the units were providing the maintenance of the multi-functionality of the central space.

\section{Multi-functional Sitting Room and the Inconspicuous Objects}

This phenomenon is named and defined through the analysis of the adoption of the new dwelling types and 'Western' furniture after the establishment of the Republic of Turkey in 1923. Turkish society went through a series of transformations through the Westernization and Modernization processes in a political context (Bozdoğan, 2001). 'Modern' cultural and material practices were promoted and mediated by the government through different means and organs for the replacement of the traditional practices including the conventions of home cultures. Apartment buildings became the basic housing typology with functional differentiations for the rooms like living room, bedroom, bathroom, study room etc. Relevantly, different types of furniture stereotypes were considered to decorate different types of rooms.

It was an important issue to construct 'modern' and 'Western' identities through material culture in the living room which was the public stage of the domestic interiors. These furniture units were much different than the vernacular units. They were stable, static, heavy and difficult to move. Displaying this furniture became an important issue throughout the households. The living room was systematically kept clean and tidy; being isolated from the everyday practices and dedicated for formal occasions. Locking the door of the living room was even a common practice for sustaining a high level of cleanliness and maintenance.

With the devotion of the living room for formal occasions, a multi-functional room which was called as 'family sitting room' served for the everyday domestic practices of the household. The family members usually sat, rested, gathered together in this room. The television was usually placed in this room. Ayata (1984) even mentions about the practices about preparing food by watching TV in this room. It could also be used as the sleeping space of the elderly grandparents and children. Shortly, this room was experienced as a multi-functional room for the everyday practices of the household.

Ayata (1984) makes a distinction between the material qualities of the units of the living room and the family sitting room in terms of use function and the economic value. He defines the artifacts of the sitting room as ordinary, inconspicuous, low-cost but with a high level of use value. The furniture and the other items of the living room are defined as expensive, luxurious, and conspicuous while being at a very low level by means of use value.

The living atmosphere of the multi-functional family sitting room is also defined as comfortable, cozy, and informal while the mood of the living room is considered as formal and uncomfortable because of the formalities actualized for guest occasions (Ayata, 1984). 
theme 2

memory strand 1

design histories: tradition, transgression and transformations

\section{Multi-functional Living Room and the Multi-functional Objects}

This phenomenon is named and defined through the content and visual analysis of the recent home and decoration magazines (Evim, 2011 - 2012; Home-Art, 2011 - 2012). For this part of the study, the role of the cultural industries for mediating cultural practices is referred (Featherstone, 1991).

With the adoption of the neo-liberal policies and taking part in the global economies, more global cultural practices emerged throughout the Turkish society. These social changes effected the cultural dispositions and lifestyles in a manner that was favoring individuality and informality (Featherstone, 1991). Through the analysis, it was seen that the contemporary living room is mediated as being defined with rather informal and self-oriented practices without being devoted to formal occasions. Living room is mostly presented as a multi-functional space for the everyday practices like eating, studying, sitting, resting, watching television, listening to music as well as guest serving. Visual analysis and content analysis both support the multi-functional quality of the living room through both private and public dimensions:

'Living room: a space in which you can eat your meals, serve your guests, watch $T V$, read books; have individual activities or get together with your family. It is like a compact living area which serves for different functions' (Evim, December, 2011, p. 198.)

Accompanying the living room, the units and the furniture are also observed to have multifunctional qualities.

Like in the Figure 1, the armchair is transformed to a comfortable study unit and area with a mobile laptop tray. It was also observed that the armchairs are also produced as eating and drinking corners with food trays. In this case, it is possible to mention about the multi-functional qualities of the units that are provided with the relevant equipments that actualize the certain function.

Figure 1.

'With Deria laptop tray, I can enjoy my armchair as am writing' (2011) Evim, December

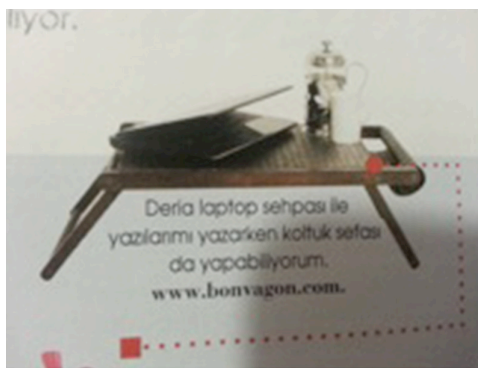

Coffee tables were addressed to perform different functions like eating snacks, reading books, etc. Also the units for accommodating different elements like TV, books, CDs, decorative objects are often observed in the analysis.

The multi - uses of the dining table for both dining and studying is also another example of the multi-functional qualities. In some situations, a multi-functional, plain and neutral table is preferred to give reference to different functions. 


\section{Conclusion}

It is seen that the notion and the qualities of multi-functionality depicts different contexts and attributes through different use practices in the context of domestic space. This brings the emergence of different phenomena that explains the relationship between the domestic space and relevant object uses.

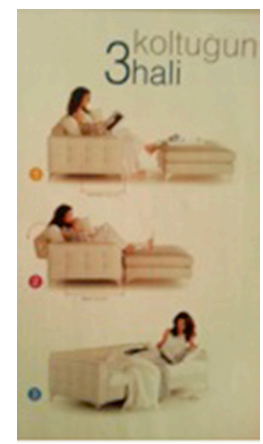

Figure 2.

An armchair design for performing different uses, Evim, December.

Through the phenomenon of 'Multi-functional Central Space and the Mobile Objects' in which the traditional and local lifestyles were prevailing in the culture, mobile units with constant functions are observed. The multi-functional attributes mostly belong to the central space of the room. For the maintenance of the dynamic space, the units have suitable qualities to be mobile. With these combinations, the same space is enabled to perform various functions in an effective way.

After the adoption of the 'Western' furniture, the performance of 'display' prevailed in the living room which is maintained in a high level of care and hygiene that even excludes the household for the sake of formal occasions. Based on this situation, the household who could not sustain their everyday practices enjoyed the family sitting room which had an inconspicuous and modest material culture opposite of the living room. 'Multi-functional Sitting Room and the Inconspicuous Objects' has been the phenomenon for explaining this kind of multi-functionality. It is still possible to meet this phenomenon throughout different segments in Turkey.

In the contemporary living rooms, informal self-oriented everyday practices are observed. The living room becomes a multi-functional space that is accompanied with multifunctional units serving for various actions.

As a result, it is seen that the notion of multi-functionality has been a valid concept throughout the repertoire of Turkish home cultures. Different contexts of multifunctionality create different uses of objects and furniture. The phenomena that are explained throughout the study are the facts that could be encountered in the different regions, different demographic groups in Turkey. The evolution and the transformation in the axe of the multi-functionality should be considered well enough for the process of domestic product design. 


\section{References}

Ayata, S. (1988). The Contest of Status and The Uses of Liiving Room in Urban Middle Class Families, Toplum ve Bilim 42, Summer 1988: 5-25

Barandır, S. (2011). Evim, Issues From January to December, İstanbul: Doğan Burda Dergi Yayıncılık ve Pazarlama A.S.

Barandır, S. (2012). Evim, Issues From January to December, İstanbul: Doğan Burda Dergi Yayıncılık ve Pazarlama A.S.

Bordieu (1984). Distinction: A Social Critique of the Judgement of Taste, London: Routledge. Bozdoğan, S. (2001). Modernism and the Nation Building, İstanbul: Metis Yayınları.

Brandes,U. (2009). Design by Use: The Everyday Metamorphosis of Things, Berlin: Birkhauser. Chaney (1999). Lifestyles, Ankara: Dost Yayınevi.

Featherstone, M. (1991). Consumer Culture and Postmodernism, London: Sage Publicaions Faroqhi, S. (2009). Men of Modest Substance: House Owners and House Property in 17th Century Ankara and Kayseri, İstanbul: Turkey İs Bankası Kültür Yayınları.

Günay, R. (1999). Turkish House Culture and Safranbolu Houses, YEM, İstanbul. Ișman, A. S. (2011). Home-Art, Issues From January to December, İstanbul: Turkuvaz Medya Grubu.

Ișman, A. S. (2012). Home-Art, Issues From January to December, Istanbul: Turkuvaz Medya Grubu.

Kıray, M. (2006). Toplumsal Yapı Toplumsal Değișme (Social Structure and Social Change), İstanbul: Bağlam Yayıncılık.

Küçükerman, Ö. (2007). Turkish House in Search of Spatial Identity, Turing, İstanbul. Nasır, E. B. (2012). A Reading on the Global Domestic Space Tendencies and Local Eating Units, 2nd International Product and Service Design Congress on Agricultural Industries, İzmir. Yürekli, F. ve Yürekli, I. (2005). Turkish House: Observations and Interpretations, İstanbul: Yapı Yayın. 